\title{
Observer trait anxiety is associated with response bias to patient facial pain expression independent of pain catastrophizing
}

\author{
Joshua A Rash MSc ${ }^{1}$, Kenneth M Prkachin $\mathrm{PhD}^{2}$, Tavis S Campbell $\mathrm{PhD}^{1}$
}

\begin{abstract}
JA Rash, KM Prkachin, TS Campbell. Observer trait anxiety is associated with response bias to patient facial pain expression independent of pain catastrophizing. Pain Res Manag 2015;20(1):39-45.
\end{abstract}

BACKGROUND: Top-down characteristics of an observer influence the detection and estimation of a sufferer's pain. A comprehensive understanding of these characteristics is important because they influence observer helping behaviours and the sufferer's experience of pain.

OBJECTIVES: To examine the hypothesis that individuals who score high in trait anxiety would perceive more intense pain in others, as indicated by a larger negative response bias, and that this association would persist after adjusting for pain catastrophizing.

METHODS: Healthy young adult participants ( $\mathrm{n}=99 ; 50$ male) watched videos containing excerpts of facial expressions taken from patients with shoulder pain and were asked to rate how much pain the patient was experiencing using an 11-point numerical rating scale. Sensitivity and response bias were calculated using signal detection methods.

RESULTS: Trait anxiety was a predictor of response bias after statistically adjusting for pain catastrophizing and observer sex. More anxious individuals had a proclivity toward imputing greater pain to a sufferer.

CONCLUSIONS: Individuals scoring higher on trait anxiety were more likely to impute pain to a sufferer. Anxious caregivers may be better able to respond with appropriate intervention once pain behaviour is detected, or they may exacerbate symptoms by engaging in excessive palliative care and solicitous behaviour.

Key Words: Pain detection; Pain estimation; Pain perception; Response bias; Trait anxiety

A ccording to the communication model of pain (1-5), private representations of pain are encoded in expressive behaviour that is communicated to an observer for decoding and interpretation. The communication and empathy (6) models for pain propose that three factors affect observer pain perception: sufferer characteristics (ie, bottom-up influences such as signal strength and clarity); observer characteristics (ie, top-down influences such as higher cognitive processes); and contextual and relational factors. Understanding how these factors influence estimation of a sufferer's pain is important because such judgments may influence observer helping behaviours, and patient experience of pain and associated suffering (6).

Clarity of the sufferer's expressive pain signal influences observer perception, with higher-intensity expressions often resulting in greater accuracy (7). Sufferers encode their pain experience in expressive behaviours such as verbal reports and nonverbal behaviours (8). One salient form of nonverbal behaviour used to communicate pain is facial expression (9). Individuals experiencing pain show reliable change in facial expression that can be decoded by observers $(10,11)$, making

\author{
L'anxiété de l'observateur associée à un biais \\ de réponse face à l'expression faciale de douleur, \\ indépendamment de la catastrophisation \\ de la douleur
}

HISTOIRE : Les caractéristiques descendantes de l'observateur influent sur la détection et l'estimation de la douleur du patient. Il est important de comprendre pleinement ces caractéristiques, car elles influent sur les comportements d'aide de l'observateur et l'expérience de douleur du patient. OBJECTIFS : Examiner l'hypothèse selon laquelle les personnes qui obtiennent un résultat élevé sur le plan de l'anxiété perçoivent une douleur plus intense chez les autres, indiquée par un biais de réponse négatif plus important, et selon laquelle cette association persisterait après rajustement compte tenu de la catastrophisation de la douleur.

MÉTHODOLOGIE : Les participants, de jeunes adultes en santé ( $n=99$; 50 hommes), ont regardé des vidéos contenant des extraits d'expressions faciales de patients ayant des douleurs à l'épaule. Ils ont été invités à classer la douleur que ces patients ressentaient à l'aide d'une échelle d'évaluation numérique à 11 points. Les biais de sensibilité et de réponse ont été calculés à l'aide de méthodes de détection des signaux.

RÉSULTATS : L'anxiété était prédictive d'un biais de réponse après rajustement statistique compte tenu de la catastrophisation de la douleur et du sexe de l'observateur. Les personnes plus anxieuses ont tendance à attribuer une plus grande souffrance au patient.

CONCLUSIONS : Les personnes ayant des résultats plus élevés sur le plan de l'anxiété étaient plus susceptibles d'attribuer une douleur à un patient. Les soignants anxieux sont peut-être mieux en mesure de réagir par une intervention adaptée une fois la douleur décelée, ou exacerbent peut-être les symptômes en optant pour une sollicitude et des soins palliatifs excessifs.

facial expression one of the most influential bottom-up determinants of another's perception of a sufferer's pain $(12,13)$.

Observer characteristics also influence estimation of pain. For example, observers are less willing to impute pain if they have more experience with pain (14-16), or have reason to question the authenticity of pain complaints (17). Furthermore, observer expectancies about the threat value of the signal influences empathy for pain (6). In threatening situations, such as end-stage cancer, family caregivers overestimate patient pain (18). Similarly, individuals engaging in pain catastrophizing (ie, magnifying symptoms of pain, ruminating about pain and feeling helpless when faced with pain [19]) are more attentive to pain signals $(20,21)$, experience higher levels of emotional distress about the pain of a spouse (22) and give higher estimates of others' pain (23-25).

Theory and research suggests that observer anxiety may also be associated with heightened observer estimation of pain. Anxiety is a future-oriented affective state characterized by worry about threat or danger (26). Theory suggests that a preattentive threat-appraisal

${ }^{1}$ Department of Psychology, University of Calgary, Calgary, Alberta; ${ }^{2}$ Department of Psychology, University of Northern British Columbia, Prince George, British Columbia

Correspondence: Mr Joshua A Rash, Department of Psychology, University of Calgary, 2500 University Drive Northwest, Calgary, Alberta T2N 1N4. Telephone 403-483-7997, fax 403-282-8249, e-mail jarash@ucalgary.ca

OPEN ACCESS

This open-access article is distributed under the terms of the Creative Commons Attribution Non-Commercial License (CC BY-NC) (http:// creativecommons.org/licenses/by-nc/4.0/), which permits reuse, distribution and reproduction of the article, provided that the original work is properly cited and the reuse is restricted to noncommercial purposes. For commercial reuse, contact support@pulsus.com 
circuit is hypersensitive in anxious individuals, resulting in hypervigilance to and elaboration of threat (27-29). Threatening stimuli are hypothesized to feed into a resource-allocation system, and elicit physiological arousal and allocation of cognitive resources toward the stimuli (30). In fact, selective attention to threat is the central cognitive bias underlying vulnerability to and maintenance of anxiety (28,31-33). In support of this, anxious individuals have been reported to identify minor threat cues in the environment (34), and show attention biases toward fearful faces $(35,36)$. Thus, anxious individuals may be hypervigilant to pain signals in others (37), misinterpreting ambiguous signals as signifying greater pain.

Pain catastrophizing and anxiety are two negative emotion processes with significant construct overlap. Catastrophizing has been described as the cognitive component of anxiety and depression (38). Beck et al (39) initially described catastrophizing as a maladaptive cognitive style used by patients with anxious and depressed mood that is characterized by the tendency to magnify, exaggerate or ruminate about a real or perceived threat. Both pain catastrophizing and anxiety are characterized by attention to threat, overemphasis on the probability of a catastrophic outcome, and rumination about the worst possible consequences $(19,40,41)$. There is reason to believe that attention processes shared by pain catastrophizing and trait anxiety are associated with biases toward behavioural expressions of pain. According to attention theory (42), pain expressions are evolutionarily adaptive and ontogenetically primitive because they convey threatrelevant information, permit recognition of potential danger and provide opportunity for harm avoidance $(4,43)$. In support of this theory, evidence suggests that the detection of pain is primarily influenced by its inherent threat value rather than empathic concern (44).

While evidence indicates that both trait anxiety and pain catastrophizing predict personal experiences of pain (reviewed in Quartana et al [45] and Asmundson and Katz [46]), theoretical distinctions between the two constructs suggest that trait anxiety may be more relevant than pain catastrophizing when detecting facial expressions of pain. First, pain catastrophizing is a specific set of pain-related cognitive processes, whereas anxiety is characterized by a broader array of threat-related cognitive processes that, while not specific to pain, could influence the estimation of pain. For example, the information-processing apparatus in anxiety will inappropriately generate threat meaning to innocuous stimuli (40) and such innocuous stimuli may influence pain estimation apart from pain catastrophizing. Similarly, anxious individuals may catastrophize about non-pain-related outcomes such as social ostracism. Second, anxiety is a relatively discrete emotion that is characterized by autonomic hyperarousal (40) and a degree of autonomic specificity (47) while pain catastrophizing is a cognitive set that may lead to the experience of various emotions, some of which may increase observer estimation of facial pain expression (eg, depression or anxiety) while some may reduce observer estimation (eg, schadenfreude or anger). In support of this, studies have reported that pain catastrophizing is associated with interpersonal vindictiveness (48) and support entitlement (49). Finally, behavioural expressions of pain elicit observer distress and recent theory suggests that the central function of pain catastrophizing may be to downregulate negative affect (50). In the context of facial pain expression, pain catastrophizers may be more likely than anxious individuals to purposefully underestimate the pain of a sufferer as a means of coping with personal distress (51).

Given the evidence reviewed, we hypothesized that individuals scoring high in trait anxiety would perceive more intense pain in others, after adjusting for pain catastrophizing.

\section{METHOD}

\section{Participants}

The sample consisted of 50 male (mean $[ \pm$ SD] age $20.36 \pm 3.14$ years) and 49 female (mean age $20.59 \pm 2.52$ years) university students, the majority of whom were white $(41.4 \%)$ or Asian (37.4\%). Average education was $2.54 \pm 1.38$ years of postsecondary school. Participants were recruited through the Department of Psychology and given extra course credit for their participation.

The study protocol was approved by the Conjoint Faculty Research Ethics Board of the University of Calgary (Calgary, Alberta). All participants underwent an individual consent process and provided written consent to participate.

\section{Materials}

Participants viewed four videos consisting of the facial expressions of clinical shoulder pain among patients undergoing active and passive range-of-motion tests. The facial expressions were sampled from records taken in a previous study (52). Each video displayed a series of 90 trials that consisted of a $1 \mathrm{~s}$ facial expression followed by $1 \mathrm{~s}$ of each of the following: black screen; orientation number corresponding to the trial; and black screen. In each video, one-third of the test clips displayed a patient's face evidencing no pain, low pain and moderate pain. Pain expressiveness was defined by measurements of the intensity of four facial actions (brow lowering, orbit tightening, levator tightening and eye closure) that are reliably associated with pain $(5,10)$. Brow lowering, orbit tightening and levator tightening were coded on a six-point scale ranging from no action $(0)$ to extreme action (5). Eye closure was coded on a binary scale $(0=$ no eye closure; 1 = eye closure). The presence and intensity of facial actions were coded by observers who passed the criteria for proficiency in the Facial Action Coding System (53). Coding reliability, based on the EkmanFriesen formula, was $>0.90$ (11). Scores on brow lowering, orbit tightening, levator tightening and eye closure were summed to create an index of pain ranging from 0 to 16 . 'No pain' was defined as an index score of 0 , 'low pain' as an index score of 2 or 3, and 'moderate pain' as an index score of 5 or 6 . Expressions with an index score $>7$ were not included because ceiling effects at higher pain expressions have been observed in the authors' previous research $(15,54)$.

In each of the four videos, excerpts of male and female patients were evenly represented among the 90 test clips, such that 15 female and 15 male facial expressions were presented in each of the no pain, low pain and moderate pain categories. All facial expressions were sampled from a database containing 128 patients. Due to the constraints of the database, many patients had different facial expressions rendered at different intensities within the same video and across videos. No clips were repeated within or across a video and no patient had more than one facial expression at any given intensity. Altogether, each video spanned $6 \mathrm{~min} 12 \mathrm{~s}$. The presentation of patients and pain expressiveness were rendered into videos in a random order.

\section{Questionnaires}

Pain catastrophizing is defined as bringing an exaggerated negative mental set to bear on actual or anticipated painful experiences (55). The Pain Catastrophizing Scale (PCS) (19) is a 13-item questionnaire that measures pain catastrophizing by having participants describe thoughts and feelings that individuals may experience when they are in pain. The PCS instructions ask participants to reflect on past painful experiences and to indicate the degree to which they experienced each of 13 thoughts or feelings when experiencing pain, on five-point scales with the end points $0=$ not at all and $4=$ all the time. The PCS yields a total score and three subscale scores assessing rumination, magnification and helplessness. The PCS has been shown to have adequate to excellent internal consistency (19) ( $\alpha=0.88$ in the present sample).

The trait version of the State-Trait Anxiety Inventory (56) is a 20 -item questionnaire that measures dispositional anxiety. Representative items include: "I feel pleasant" and "I feel nervous and restless". Participants rate their level of agreement on each item ranging from 1 (almost never) to 4 (almost always). The State-Trait Anxiety Inventory has been found to be a reliable and valid measure of trait anxiety (56) ( $\alpha=0.89$ in the present sample).

\section{Procedure}

Participants completed questionnaires and then viewed each of the four videos during one individual laboratory session. Videos were 
shown using Windows Media Player (Microsoft Corporation, USA) running on a personal computer with a 17 -inch ThinkVision flatscreen monitor (Lenovo, USA). Participants sat at a self-selected distance from the screen. Participants watched each of the four videos in an order that was randomized by participant and rated the degree of pain for each test clip on a numerical rating scale ranging from 0 (no pain present) to 10 (worst pain imaginable).

\section{Data reduction}

Two independent parameters are involved in the inference about a patient's pain - sensitivity and response bias $(5,57)$. Sensitivity refers to the ability to discriminate among levels of pain, independent of the level of pain. Response bias refers to the willingness of an observer to ascribe pain to others.

For each of the four videos, participants' ratings were evaluated by signal detection methods, yielding indexes of sensitivity and response bias. Hit (correctly identifying a pain expression as painful) and false alarm (identifying a no-pain expression as painful) probabilities were calculated for each participant at each level of pain expressiveness. Hit and false alarm probabilities were then used to calculate indices of sensitivity and response bias. Sensitivity was evaluated by calculating $\mathrm{p}(\mathrm{A})$ (58), an estimate of the area under the ROC curve formed when the cumulative probability of using each category to describe a signal (in this case, low or moderate pain expressions) is represented on the ordinate, while the cumulative probability of using each category to describe noise is represented on the abscissa. Thus, two measures of the ability to discriminate pain expressions were calculated, one representing the ability to distinguish low pain from noise (ie, no pain) and one representing the ability to distinguish moderate pain from noise (ie, low pain). The values, referred to as $\mathrm{p}(\mathrm{A})_{\mathrm{L}}$ and $\mathrm{p}(\mathrm{A})_{\mathrm{M}}$, can range from 0 to 1.0. A value of 0.5 indicates chance performance or lack of ability to discriminate signal from noise.

The measure of response bias was B (58). B is a global, nonparametric measure of the point on a rating scale at which the observer is equally likely to make a hit or a false alarm. It is calculated by interpolation between the two points on a rating scale at which the cumulative probability of hits and false alarms straddle 1.0. Two measures of response bias were calculated, one representing bias to low pain $\left(B_{L}\right)$ and one representing bias to moderate pain $\left(B_{M}\right)$.

Each participant viewed four distinct videos, but the order in which each video was judged varied according to the protocol described above. For analysis, participants' $\mathrm{p}(\mathrm{A})_{\mathrm{L}}, \mathrm{p}(\mathrm{A})_{\mathrm{M}}, \mathrm{B}_{\mathrm{L}}$ and $\mathrm{B}_{\mathrm{M}}$ values were pooled according to the serial position of the video to define a four-level trial factor (for example, if participant 1 observed video A first, and participant 2 observed video B first, the trial 1 sensitivity and response bias measures for participant 1 would be based on video $A$ and for participant 2 on video B). Given that each video was created using the same number of clips, scored at the same intensities, and containing the same number of male patients, female patients, minority patients, young patients and older patients, amalgamating participant scores from various videos into a single index was deemed appropriate.

\section{Data clean-up}

Data for 101 participants (52 male and 49 female) were screened for univariate and multivariate outliers. There were no univariate outliers with a Z-score $>3.29$ (59). Multivariate outliers were assessed using Mahalanobis distances using linear regression in SPSS (IBM Corporation, USA) with participant entered as a criterion variable and relevant predictor and outcome variables entered as predictors. Two participants were identified as multivariate outliers on measures of B $\left(\chi^{2}>\chi^{2}[8]_{\text {critical }}\right.$ of 26.13), indicating that the pattern of scores on predictor and outcome variables for these two participants deviated from the centroid score of the remaining participants by values in excess of $\mathrm{P}<0.001$. Data from these two participants were removed.

It was of interest to determine whether indices of $\mathrm{p}(\mathrm{A})$ and $\mathrm{B}$ varied as a function of repeated exposure. A 4 (Exposure: trial 1, trial 2, trial 3, trial 4) $\times 2$ (pain expressiveness: low, moderate $) \times 2$ (sex of the

\section{TABLE 1}

Descriptive statistics

\begin{tabular}{lrrr}
\hline Measure & \multicolumn{1}{c}{ Total } & Men & \multicolumn{1}{c}{ Women } \\
\hline Pain catastrophizing & $19.81 \pm 8.58$ & $18.38 \pm 9.28$ & $21.26 \pm 7.60$ \\
Trait anxiety & $37.11 \pm 8.67$ & $34.88 \pm 7.70$ & $39.39 \pm 9.07$ \\
p(A) low pain & $0.69 \pm 0.06$ & $0.70 \pm 0.05$ & $0.69 \pm 0.06$ \\
p(A) moderate pain & $0.71 \pm 0.04$ & $0.71 \pm 0.04$ & $0.70 \pm 0.04$ \\
B low pain & $2.23 \pm 1.18$ & $2.34 \pm 1.20$ & $2.12 \pm 1.16$ \\
B moderate pain & $4.31 \pm 1.53$ & $4.27 \pm 1.48$ & $4.35 \pm 1.60$ \\
\hline
\end{tabular}

Data presented as mean $\pm S D . n=99$ ( $n=50$ male, $n=49$ female). $p(A)$ Sensitivity; B Bias

observer: male, female) mixed-model multivariate analysis of covariance (MANCOVA) was run for $\mathrm{p}(\mathrm{A})$ and $\mathrm{B}$ adjusting for pain catastrophizing and trait anxiety. The main effects of exposure on $p(A)$ $(F[3,92]=0.72, \mathrm{P}>0.05)$ or $\mathrm{B}(F[3,92]=1.40, \mathrm{P}>0.05)$ were not significant, justifying averaging of bias and sensitivity measures across trials.

\section{Statistical analysis}

Preliminary analyses: Two 2 (pain expressiveness: low, moderate) $\times 2$ (sex: male, female) ANOVAs were performed for sensitivity and response bias to investigate the effects of pain expressiveness on $\mathrm{p}(\mathrm{A})$ and $\mathrm{B}$.

Anxiety and pain catastrophizing as predictors of sensitivity and response bias to low pain and moderate pain: To test our hypotheses, hierarchical linear regressions were used to assess whether trait anxiety was a unique predictor of $\mathrm{p}(\mathrm{A})_{\mathrm{L}}, \mathrm{p}(\mathrm{A})_{\mathrm{M}}, \mathrm{B}_{\mathrm{L}}$ and $\mathrm{B}_{\mathrm{M}}$ after statistically adjusting for pain catastrophizing, and observer sex. $\mathrm{p}(\mathrm{A})_{\mathrm{L}}$ was entered as the outcome variable and observer sex was entered in step 1 as a control variable. Pain catastrophizing and trait anxiety were entered in Step 2 and Step 3 as predictor variables, respectively. Similar regression analyses were performed with $\mathrm{p}(\mathrm{A})_{\mathrm{M}}, \mathrm{B}_{\mathrm{L}}$ and $\mathrm{B}_{\mathrm{M}}$ as outcome variables.

\section{RESULTS}

The mean \pm SD pain catastrophizing $(19.81 \pm 8.58)$ and trait anxiety $(37.11 \pm 8.67)$ scores of the sample were comparable with population norms $(19,56)$. An independent-samples $t$ test was used to evaluate whether pain catastrophizing or trait anxiety varied according to sex of the observer. Trait anxiety $(t[97]=2.67, \mathrm{SEM}=1.69, \mathrm{P}<0.01)$, but not pain catastrophizing $(t[97]=1.69, \mathrm{SEM}=1.71, \mathrm{P}>0.05)$, varied according to sex of the observer. Female observers' scores on anxiety $(39.3 \pm 9.07)$ were higher than male observers' scores $(34.88 \pm 7.70)$. Descriptive statistics for $p(A)_{L}, p(A)_{M}, B_{L}$ and $B_{M}$ are presented in Table 1. Of interest, there was a moderate positive association between trait anxiety and pain catastrophizing $(\mathrm{r}=0.31 ; \mathrm{P}<0.05)$.

Preliminary analysis: The effect of pain expressiveness on $p(A)$ There was a main effect of pain expressiveness on $p(A)(F[1,97]=5.64$, $\left.\mathrm{SEM}=0.001, \mathrm{P}<0.05, \eta_{\mathrm{p}}{ }^{2}=0.06\right)$. Greater sensitivity was observed for moderate pain expressions (mean \pm SE $0.705 \pm 0.004$ ) than for low pain expressions $(0.695 \pm 0.006)$. There was no effect of sex on $p(A)$ $\left(F[1,97]=0.57, \mathrm{SEM}=0.01, \mathrm{P}>0.05, \eta_{\mathrm{p}}{ }^{2}=0.01\right)$ and no sex $\times$ pain expressiveness interaction $\left(F[1,97]=1.46, \mathrm{SEM}=0.004, \mathrm{P}>0.05, \eta_{\mathrm{p}}{ }^{2}=0.02\right)$.

Preliminary analysis: The effect of pain expressiveness on $\mathrm{B}$ There was a main effect of pain expressiveness on $B(F[1,97]=490.54$, $\left.\mathrm{SEM}=0.44, \mathrm{P}<0.01, \eta \mathrm{p}^{2}=0.84\right)$. A greater response bias was observed for moderate pain expressions $(4.31 \pm 0.16)$ than for low pain expressions $(2.34 \pm 0.12)$. There was no effect of sex on $B(F[1,97]=0.07$, $\left.\mathrm{SEM}=3.33, \mathrm{P}>0.05, \eta \mathrm{p}^{2}=0.00\right)$, and no sex $\times$ pain expressiveness interaction $\left(F[1,97]=2.49, \mathrm{SEM}=0.44, \mathrm{P}>0.05, \eta_{\mathrm{p}}{ }^{2}=0.02\right)$.

Pain catastrophizing and anxiety as predictors of $\mathrm{p}(\mathrm{A})$ for low pain expression

In the analysis of $\mathrm{p}(\mathrm{A})_{\mathrm{L}}$, the final regression model was not significant $(\mathrm{R}=0.16, \mathrm{~F}[3,95]=0.88, \mathrm{SEM}=0.003, \mathrm{P}>0.05)$. The $\mathrm{R}^{2}$ value of 0.027 indicated that sex, pain catastrophizing and anxiety accounted for $2.7 \%$ of the variability in $\mathrm{p}(\mathrm{A}) \mathrm{L}$. Sex $(b=-0.014, t=1.23, \mathrm{P}>0.05)$, 
TABLE 2

Summary of multiple regression analysis for bias to low pain

\begin{tabular}{|c|c|c|c|c|c|c|c|c|c|}
\hline \multirow[b]{2}{*}{ Variable } & \multicolumn{3}{|c|}{ Model 1} & \multicolumn{3}{|c|}{ Model 2} & \multicolumn{3}{|c|}{ Model 3} \\
\hline & $b$ & SE $b$ & $t$ & $b$ & SE $b$ & $t$ & $b$ & SE $b$ & $t$ \\
\hline Sex & -0.22 & 0.24 & 0.91 & -0.30 & 0.24 & 1.26 & -0.40 & 0.24 & 1.68 \\
\hline Catastrophizing & & & & 0.03 & 0.01 & $2.08^{*}$ & 0.02 & 0.01 & 1.26 \\
\hline$\Delta R^{2}$ & & & 0.01 & & & 0.043 & & & 0.039 \\
\hline$F$ for change in $R^{2}$ & & & 0.82 & & & $4.31^{*}$ & & & $4.08^{*}$ \\
\hline
\end{tabular}

$n=99 ;{ }^{*} P<0.05$

TABLE 3

Summary of multiple regression analysis for bias to moderate pain

\begin{tabular}{|c|c|c|c|c|c|c|c|c|c|}
\hline \multirow[b]{2}{*}{ Variable } & \multicolumn{3}{|c|}{ Model 1} & \multicolumn{3}{|c|}{ Model 2} & \multicolumn{3}{|c|}{ Model 3} \\
\hline & $b$ & SE $b$ & $\boldsymbol{t}$ & $b$ & SE $b$ & $t$ & $b$ & SE $b$ & $t$ \\
\hline Sex & 0.08 & 0.31 & 0.26 & -0.05 & 0.30 & 0.16 & -0.17 & 0.31 & 0.55 \\
\hline Catastrophizing & & & & 0.05 & 0.02 & $2.54^{*}$ & 0.03 & 0.02 & 1.77 \\
\hline Anxiety & & & & & & & 0.03 & 0.02 & $2.03^{*}$ \\
\hline$\Delta \mathrm{R}^{2}$ & & & 0.00 & & & 0.063 & & & 0.031 \\
\hline$F$ for change in $R^{2}$ & & & 0.07 & & & $6.44^{*}$ & & & $4.14^{*}$ \\
\hline
\end{tabular}

$n=99 ;{ }^{*} P<0.05$

pain catastrophizing $(b=0.001, t=1.03, \mathrm{P}>0.05)$ and anxiety $(b=0.000$, $t=0.54, \mathrm{P}>0.05)$ were not predictors of $\mathrm{p}(\mathrm{A})_{\mathrm{L}}$.

Pain catastrophizing and anxiety as predictors of $\mathrm{p}(\mathrm{A})$ for moderate pain expression

In the analysis of $\mathrm{p}(\mathrm{A})_{\mathrm{M}}$, the final regression model was not significant $(R=0.19, F[3,95]=1.18, S E M=0.002, P>0.05)$. The $R^{2}$ value of 0.036 indicated that sex, pain catastrophizing and anxiety accounted for $3.6 \%$ of the variability in $\mathrm{p}(\mathrm{A})_{\mathrm{M}}$. Sex $(b=-0.005, t=0.55$, $\mathrm{P}>0.05)$, pain catastrophizing $(b=0.001, t=1.18, \mathrm{P}>0.05)$ and anxiety $(b=-0.001, t=1.55, \mathrm{P}>0.5)$ were not predictors of $\mathrm{p}(\mathrm{A})_{\mathrm{M}}$.

Pain catastrophizing and anxiety as predictors of B to low pain expression

In the analysis of $\mathrm{B}_{\mathrm{L}}$, the final regression model was significant $(\mathrm{R}=0.30, F[3,95]=3.14, \mathrm{SEM}=1.31, \mathrm{P}<0.05)$. The $\mathrm{R}^{2}$ value of 0.09 indicated that sex, pain catastrophizing and anxiety accounted for $9 \%$ of the variability in $\mathrm{B}_{\mathrm{L}}$ (Table 2 ). In step 2, after adjusting for sex, pain catastrophizing $(b=0.029, t=2.07, \mathrm{P}<0.05)$ was a significant predictor of $\mathrm{B}_{\mathrm{L}}$, accounting for $4.3 \%$ of unique variance. In step 3 , after adjusting for sex and pain catastrophizing, anxiety $(b=0.03, t=2.02$, $\mathrm{P}<0.05$ ) was a significant predictor of $\mathrm{B}_{\mathrm{L}}$, accounting for $3.9 \%$ of unique variance. The unstandardized beta of 0.039 indicated that for every one unit increase in trait anxiety, there is a 0.039 increase in $B_{L}$. As trait anxiety increased, participants became more willing to impute pain to a sufferer encoding low pain signals. Importantly, pain catastrophizing was no longer a significant predictor of $B_{L}$ when trait anxiety was entered into the model (Table 2).

Pain catastrophizing and anxiety as predictors of B to moderate pain expression

In the analysis of $\mathrm{B}_{\mathrm{M}}$, the final regression model was significant $(\mathrm{R}=0.31, F[3,95]=3.31, \mathrm{SEM}=2.20, \mathrm{P}<0.05)$. The $\mathrm{R}^{2}$ value of 0.10 indicated that sex, pain catastrophizing and anxiety accounted for $10 \%$ of the variability in $B_{M}$ (Table 3 ). In step 2, after adjusting for sex, pain catastrophizing $(b=0.046, t=2.54, \mathrm{P}<0.05)$ was a significant predictor of $\mathrm{B}_{\mathrm{M}}$, accounting for $6.3 \%$ of unique variance. In step 3 , after adjusting for sex and pain catastrophizing, anxiety $(b=0.039, t=2.03$, $\mathrm{P}<0.05$ ) was a significant predictor of $\mathrm{B}_{\mathrm{M}}$, accounting for $3.1 \%$ of unique variance. The unstandardized beta of 0.031 indicated that for every one unit increase in trait anxiety there is a 0.031 increase in $B_{M}$. As trait anxiety increased, participants became more willing to impute pain to a sufferer encoding moderate pain signals. Importantly, pain catastrophizing was no longer a significant predictor of $B_{M}$ when trait anxiety was entered into the model (Table 3).

\section{DISCUSSION}

Healthy young adults watched videos containing excerpts of facial expressions taken from patients with clinical shoulder pain and were asked to rate how much pain the patient was experiencing. Preliminary analyses indicated that sensitivity and response bias were influenced by pain expressiveness, such that participants were more accurate in their estimation and more willing to impute pain to a sufferer when discriminating between low-pain and moderate-pain expressions than between no-pain and low-pain expressions. Primary analyses indicated that participants scoring higher in trait anxiety inferred more intense pain for both male and female sufferers, and this effect persisted after adjusting for other observer characteristics (ie, pain catastrophizing and sex). Thus, the results of the present study support our primary hypothesis and suggest that individuals with high levels of trait anxiety are likely to impute greater pain to the pain expressions of shoulder pain patients. Interestingly, trait anxiety was not associated with differential ability to discriminate no, low and moderate levels of facial pain expression.

Higher scores on trait anxiety were associated with a greater willingness to impute pain to patients with clinical shoulder pain. To our knowledge, this is the first time that such a finding has been reported. Anxiety, it appears, amplifies an observer's evidence about pain signals coming from a patient, suggesting hypersensitivity of the threatappraisal circuits. These findings are congruent with attentional and processing biases found in anxious individuals. Anxious individuals have been found to display a reliable bias in attentional processing that favours threat-related information (30). Pain behaviours signal potential danger and provide the observer an opportunity to avoid harm (3). Observers scoring higher on trait anxiety may be decoding the facial pain messages of the patient as conveying a greater sense of threat in the environment.

Consistent with previous research, pain estimates were influenced by the levels of catastrophizing of the observer $(20,21,24,60)$. The results of the present research extend previous findings by demonstrating that trait anxiety accounts for observer estimates of pain in addition to pain catastrophizing. While little empirical research exists on the topic, there are several reasons why trait anxiety may be associated with observer judgment of facial pain expression after adjusting for pain catastrophizing. First, trait anxiety may be associated with 
favourable evaluations of sufferer attributions (eg, likability, deservingness of support) which, in turn, influence judgment of facial pain expression. For example, observers have been reported to estimate lower pain among patients whose images were previously associated with negative traits (61), who were characterized as opioid seeking (17) or who were physically attractive (62). Interestingly, pain catastrophizers report self-oriented traits, such as interpersonal vindictiveness (48) and support entitlement (49), which may be associated with lower observer estimates of facial pain expression. Second, greater experience with pain has been associated with observer underestimation $(14,15,57,63)$ and it is possible (although not yet tested) that anxious individuals have less knowledge and learning experiences with pain than pain catastrophizers. The pervasive nature of anxiety may reduce the likelihood of anxious individuals engaging in activities that are likely to result in injury and pain. Third, theoretical conceptualizations suggest that anxiety is a higher-order cognitive factor characterized by generalized worry, fear and distress about future events, while catastrophizing is a lower-order cognitive factor where worry, fear and distress are specific to catastrophes (64-66). The general nature of anxiety could results in heightened negative affect that may influence observer judgment of facial pain expression. Recently, an association was reported between pain catastrophizing and several indexes of negative mood, with pain catastrophizing accounting for minimal variance in pain outcomes above negative mood (67). Fourth, autonomic hyperarousal, characteristic of anxiety (47), may enhance observer judgment of pain by providing sensory input to the pain neuromatrix during pain estimation. Studies have reported that parts of the pain matrix associated with the affective component, but not sensory component, of pain are activated when viewing facial pain expression $(12,68)$. It is possible, therefore, that autonomic hyperarousal activates sensory components of the neuromatrix. In partial support of this, anxiety sensitivity (ie, the proclivity to interpret somatic symptoms as aversive or dangerous) shares a robust association with the experience of pain and the fearful appraisal of pain (69). Moreover, one recent prospective trial reported trait anxiety was associated with the development of temperomandibular disorder among 3263 pain-free patients (70). Of interest, somatic symptoms were the psychological variables that differed most markedly between cases and controls in this cohort (71). Finally, behavioural expressions of pain result in observer distress (4) and observers may be motivated to reduce distress through avoidance, escape or purposeful underestimation of pain $(44,72)$. Pain catastrophizing is characterized by rumination about pain and feelings of helplessness surrounding pain, which have been reported to result in heightened personal distress (22,73-76). Empirical evidence suggests that pain catastrophizers are motivated to reduce their personal distress by engaging in protective behaviours to reduce pain (74). Pain catastrophizers in our study may have been motivated to reduce personal distress through purposeful underestimation, given that no relationship was present between the observer and patients. This interpretation coincides with recent theoretical conceptualization of pain catastrophizing as repetitive negative thinking that serves the function to downregulate negative affect (50). Additional rigorous research is needed to systematically evaluate the associations between trait anxiety, pain catastrophizing and observer pain estimation before the shared and unique effects can be better understood.

The relationship between trait anxiety and heightened response bias of others' pain may have implications for how anxiety might influence caregiving behaviour. One possibility is that anxious caregivers may be better able to respond with appropriate intervention to pain behaviours once they are detected. However, an anxious caregiver may overestimate the pain of a sufferer and believe that pain is present when it is minimal or absent. The reactions of the anxious caregiver may elicit in the sufferer a re-evaluation of the pain as more serious than initially believed (6). Similarly, an anxious caregiver of a chronic pain patient may be motivated to engage in excessive palliative care or solicitous behaviour to reduce the patient's distress, and inadvertently contribute to increased disability (77-79).
Several limitations must be acknowledged. Participants were exposed to four videos, each containing an identical number of facial pain expressions presented at no, low and moderate pain, which could have overburdened the perceptual system and resulted in participant fatigue. This appears to be unlikely, given that there was no difference in sensitivity and bias across video presentation. Excerpts of facial pain expressions were brief in duration and presented in rapid succession. Presenting a $1 \mathrm{~s}$ facial pain expression every $4 \mathrm{~s}$ requires automatic processing and leaves little time for evaluation. This hurried decision making may have contributed to the bias in high trait anxiety observers. Individuals scoring high in trait anxiety have been found to focus on threat-related information during immediate processing, but to shift their focus to safe areas when processing is deliberate $(80)$. The present research was a laboratory controlled investigation with limited clinical research to support its real-world generalizability. As such, additional clinical research in this area is needed before the results of this investigation can be extrapolated to clinical settings. Finally, because the present study assessed undergraduate university students using artificial levels of exposure in highly controlled laboratory circumstances, the results may not generalize to widely different populations and circumstances. Nevertheless, the methods have much strength, including the use of a well-validated paradigm that mimics the natural judgment process and the use of stimulus materials obtained in a natural clinical setting with ecological validity.

\section{SUMMARY}

The present study provides evidence that observer trait anxiety affects judgment biases, enhancing willingness to impute pain, without compromising sensitivity to discriminate between no-pain, low-pain and moderate-pain expressions. The results suggest that anxious individuals infer greater pain when viewing facial pain expressions. Furthermore, the effects of observer trait anxiety on the detection of others' pain persisted after controlling for pain catastrophizing, suggesting that a negative affective style that generalizes to catastrophes beyond pain is an important top-down influence of observer pain estimation. Additional research into the underlying mechanisms and into the caregiver consequences of decisions made by more or less anxious caregivers is needed.

DISCLOSURES: All authors contributed to study design, data collection and manuscript preparation. All authors discussed the results of this manuscript and commented on the finished product. The authors have no conflicts of interest pertaining to the material presented in this article.

FUNDING STATEMENT: This research project was funded by trainee grants from Alberta Innovates Health Solutions and the Canadian Institutes for Health Research.

\section{REFERENCES}

1. Craig KD. The social communication model of pain. Can Psychol 2009;50:22

2. Hadjistavropoulos T, Craig K. A theoretical framework for understanding self-report and observational measures of pain: A communications model. Behav Res Ther 2002;40:551-70.

3. Hadjistavropoulos T, Craig KD. Social influences and the communication of pain. In: H Hadjistavropoulos T, Craig KD, eds. Pain: Psychological Perspectives. New York: Lawrence Erlbaum, 2004;87-112.

4. Hadjistavropoulos T, Craig KD, Duck S, et al. A biopsychosocial formulation of pain communication. Psychol Bull 2011;137:910-39.

5. Prkachin KM, Craig K. Expressing pain: The communication and interpretation of facial pain signals. J Nonverbal Behavior 1995;19:191-205.

6. Goubert L, Craig KD, Vervoort T, et al. Facing others in pain: The effects of empathy. Pain 2005;118:285-8 
7. Craig K, Prkachin KM, Grunau RVE. The facial expression of pain. In: DC Turk, R Melzack, eds. Handbook of Pain Assessment. New York: Guilford Press, 2011;117-33.

8. Keefe FJ, Williams DA, Smith SJ. Assessment of pain behaviors. In: Turk DC, Melzack R, eds. Handbook of Pain Assessment. New York: Guilford Press, 2001;170-87.

9. Schiavenato M, Byers J, Scovanner P, Windya P, Shah M. Is there a primal face of pain? A methodology answer. Conf Proc IEEE Eng Med Biol Soc 2007;2007:3559-62.

10. Prkachin KM. The consistency of facial expressions of pain: A comparison across modalities. Pain 1992;51:297-306.

11. Prkachin KM, Solomon PE. The structure, reliability and validity of pain expression: Evidence from patients with shoulder pain. Pain 2008;139:267-74.

12. Botvinick M, Jha AP, Bylsma LM, Fabian SA, Solomon PE, Prkachin KM. Viewing facial expressions of pain engages cortical areas involved in the direct experience of pain. Neurolmage 2005;25:312-9.

13. Williams AC. Facial expression of pain: An evolutionary account. Behav Brain Sci 2002;25:439-55.

14. Prkachin KM, Solomon PE, Hwang T, Mercer SR. Does experience affect judgements of pain behaviour? Evidence from relatives of pain patients and health-care providers. Pain Res Manag 2001;6:105-12.

15. Prkachin KM, Mass H, Mercer SR. Effects of exposure on perception of pain expression. Pain 2004;111:8-12.

16. Prkachin KM, Rocha EM. High levels of vicarious exposure bias pain judgments. J Pain 2010;11:904-9.

17. Kappesser J, Williams AC, Prkachin KM. Testing two accounts of pain underestimation. Pain 2006;124:109-16.

18. Redinbaugh EM, Baum A, DeMoss C, Fello M, Arnold R. Factors associated with the accuracy of family caregiver estimates of patient pain. J Pain Symptom Manag 2002;23:31-8.

19. Sullivan MJ, Bishop SR, Pivik J. The pain catastrophizing scale: Development and validation. Psychol Assess 1995;7:524.

20. Sullivan M, Martel M, Tripp D, Savard A, Crombez G. Catastrophic thinking and heightened perception of pain in others. Pain 2006;123:37-44.

21. Van Damme S, Crombez G, Lorenz J. Pain draws visual attention to its location: Experimental evidence for a threat-related bias. J Pain 2007;8:976-82.

22. Leonard MT, Cano A. Pain affects spouses too: Personal experience with pain and catastrophizing as correlates of spouse distress. Pain 2006;126:139-46.

23. Goubert L, Craig KD, Buysse A. Perceiving others in pain: Experimental and clinical evidence on the role of empathy. Soc Neurosci Empathy 2009:153-66.

24. Martel M, Thibault P, Roy C, Catchlove R, Sullivan M. Contextual determinants of pain judgments. Pain 2008;139:562-8.

25. Pincus T, Morley S. Cognitive-processing bias in chronic pain: A review and integration. Psychol Bull 2001;127:599.

26. Barlow DH. Unraveling the mysteries of anxiety and its disorders from the perspective of emotion theory. Am Psychol 2000;55:1247-63.

27. Cisler JM, Koster EH. Mechanisms of attentional biases towards threat in anxiety disorders: An integrative review. Clin Psychol Rev 2010;30:203-16.

28. Mathews A. Why worry? The cognitive function of anxiety. Behav Res Ther 1990;28:455-68.

29. Sylvers P, Lilienfeld SO, LaPrairie JL. Differences between trait fear and trait anxiety: Implications for psychopathology. Clin Psychol Rev 2011;31:122-37.

30. Bar-Haim Y, Lamy D, Pergamin L, Bakermans-Kranenburg MJ, van IJzendoorn MH. Threat-related attentional bias in anxious and nonanxious individuals: A meta-analytic study. Psychol Bull 2007;133:1-24.

31. Williams J, Watts F, MacLeod C, Mathews A. Cognitive Psychology and Emotional Disorders, 2nd edn. New York: Jolm Wiley \& Sons, 1997.

32. Eysenck MW. Anxiety: The Cognitive Perspective. Hove: Lawrence Erlbaum Associates Inc, 1992.

33. Eysenck MW, Derakshan N, Santos R, Calvo MG. Anxiety and cognitive performance: Attentional control theory. Emotion 2007;7:336.

34. Mogg K, Millar N, Bradley BP. Biases in eye movements to threatening facial expressions in generalized anxiety disorder and depressive disorder. J Abnormal Psychol 2000;109:695.

35. Fox E. Processing emotional facial expressions: The role of anxiety and awareness. Cogn Affect Behav Neurosci 2002;2:52-63.
36. Surcinelli P, Codispoti M, Montebarocci O, Rossi N, Baldaro B. Facial emotion recognition in trait anxiety. J Anxiety Disord 2006;20:110-17.

37. Crombez G, Van Damme S, Eccleston C. Hypervigilance to pain: An experimental and clinical analysis. Pain 2005;116:4-7.

38. Lazarus RS, Folkman. Stress. New York: Springer Publishing Company, 1984.

39. Beck A, Rush A, Shaw B, Emery G. Cognitive Therapy of Depression. New York: Guilford, 1979.

40. Beck AT, Clark DA. An information processing model of anxiety: Automatic and strategic processes. Behav Res Ther 1997;35:49-58.

41. Turner JA, Aaron LA. Pain-related catastrophizing: What is it? Clin J Pain 2001;17:65-71.

42. Eccleston C, Crombez G. Pain demands attention: A cognitive-affective model of the interruptive function of pain. Psychol Bull 1999;125:356.

43. Craig KD, Versloot J, Goubert L, Vervoort T, Crombez G. Perceiving pain in others: Automatic and controlled mechanisms. J Pain 2010;11:101-8.

44. Yamada M, Decety J. Unconscious affective processing and empathy: An investigation of subliminal priming on the detection of painful facial expressions. Pain 2009;143:71-5.

45. Quartana PJ, Campbell CM, Edwards RR. Pain catastrophizing: A critical review. Exp Rev Neurother 2009;9:745-58.

46. Asmundson GJ, Katz J. Understanding the co-occurrence of anxiety disorders and chronic pain: State-of-the-art. Depress Anxiety 2009;26:888-901.

47. Kreibig SD. Autonomic nervous system activity in emotion: A review. Biol Psychol 2010;84:394-421.

48. Lackner JM, Gurtman MB. Pain catastrophizing and interpersonal problems: A circumplex analysis of the communal coping model. Pain 2004;110:597-604.

49. Cano A, Leong L, Heller JB, Lutz JR. Perceived entitlement to pain-related support and pain catastrophizing: Associations with perceived and observed support. Pain 2009;147:249-54.

50. Flink IL, Boersma K, Linton SJ. Pain catastrophizing as repetitive negative thinking: A development of the conceptualization. Cogn Behav Ther 2013;42:215-23.

51. Batson CD. The Altruism Question: Toward a Social-Psychological Answer. Hove: Lawrence Erlbaum Associates Inc, 1991.

52. Prkachin KM, Mercer SR. Pain expression in patients with shoulder pathology: Validity, properties and relationship to sickness impact. Pain 1989;39:257-65.

53. Ekman P, Friesen WV. The Facial Action Coding System. Palo Alto: Consulting Psychologists Press, 1978.

54. Deyo KS, Prkachin KM, Mercer SR. Development of sensitivity to facial expression of pain. Pain 2004;107:16-21.

55. Sullivan MJ, Thorn B, Haythornthwaite JA, et al. Theoretical perspectives on the relation between catastrophizing and pain. Clin J Pain 2001;17:52-64.

56. Spielberger CD, Gorsuch RL, Lushene R, Vagg PR, Jacobs GA. Manual for the state-trait anxiety inventory. Palo Alto: Consulting Psychologists Press, 1983.

57. Prkachin KM, Solomon PE, Ross J. Underestimation of pain by health-care providers: Towards a model of the process of inferring pain in others. Can J Nurs Res 2007;39:88-106.

58. McNicol D. A Primer of Signal Detection Theory. Mahwah: Lawrence Erlbaum Associates, 2005.

59. Tabachnick BG, Fidell LS. Using Multivariate Statisitcs. Boston: Pearson, 2012.

60. Goubert L, Vervoort T, Cano A, Crombez G. Catastrophizing about their children's pain is related to higher parent-child congruency in pain ratings: An experimental investigation. Eur J Pain 2009;13:196-201.

61. De Ruddere L, Goubert L, Prkachin KM, Stevens MA, Van Ryckeghem DM, Crombez G. When you dislike patients, pain is taken less seriously. Pain 2011;152:2342-7.

62. Hadjistavropoulos HD, Ross MA, Von Baeyer CL. Are physicians' ratings of pain affected by patients' physical attractiveness? Soc Sci Med 1990;31:69-72.

63. Cheng Y, Lin C-P, Liu H-L, et al. Expertise modulates the perception of pain in others. Curr Biol 2007;17:1708-13.

64. Keogh E, Asmundson GJ. Negative affectivity, catastrophizing, and anxiety sensitivity. In: Asmundson GJ, Vlaeyen JW, Crombez G, eds. Understanding and Treating Fear of Pain. Oxford: Oxford University Press, 2004:91-115.

65. Riskind JH. Looming vulnerability to threat: A cognitive paradigm for anxiety. Behav Res Ther 1997;35:685-702. 
66. Riskind JH, Williams NL. Specific cognitive content of anxiety and catastrophizing: Looming vulnerability and the looming maladaptive style. J Cogn Psychother 1999;13:41-54.

67. Hirsh AT, George SZ, Riley JL, Robinson ME. An evaluation of the measurement of pain catastrophizing by the coping strategies questionnaire. Eur J Pain 2007;11:75.

68. Jackson PL, Meltzoff AN, Decety J. How do we perceive the pain of others? A window into the neural processes involved in empathy. NeuroImage 2005;24:771-9.

69. Ocañez KL, Kathryn McHugh R, Otto MW. A meta-analytic review of the association between anxiety sensitivity and pain. Depress Anxiety 2010;27:760-7.

70. Fillingim RB, Ohrbach R, Greenspan JD, et al. Psychological factors associated with development of TMD: The OPPERA prospective cohort study. J Pain 2013;14:T75-T90.

71. Fillingim RB, Ohrbach R, Greenspan JD, et al. Potential psychosocial risk factors for chronic TMD: Descriptive data and empirically identified domains from the OPPERA case-control study. J Pain 2011;12:T46-T60.

72. Vachon-Presseau E, Martel MO, Roy M, Caron E, Jackson PL, Rainville P. The multilevel organization of vicarious pain responses: Effects of pain cues and empathy traits on spinal nociception and acute pain. Pain 2011;152:1525-31.

73. Caes L, Goubert L, Sullivan M, Chambers CT. Catastrophic thinking about pain: A critical appraisal highlighting the importance of the social context and balance. J Symptoms Signs 2013;2:298-308.
74. Caes L, Vervoort T, Eccleston C, Vandenhende M, Goubert L. Parental catastrophizing about child's pain and its relationship with activity restriction: The mediating role of parental distress. Pain 2011;152:212-22.

75. Caes L, Vervoort T, Trost Z, Goubert L. Impact of parental catastrophizing and contextual threat on parents' emotional and behavioral responses to their child's pain. Pain 2012;153:687-95.

76. Goubert L, Vervoort T, Sullivan MJ, Verhoeven K, Crombez G. Parental emotional responses to their child's pain: The role of dispositional empathy and catastrophizing about their child's pain. J Pain 2008;9:272-9.

77. Romano JM, Jensen MP, Turner JA, Good AB, Hops H. Chronic pain patient-partner interactions: Further support for a behavioral model of chronic pain. Behav Ther 2000;31:415-40.

78. Romano JM, Turner JA, Friedman LS, Bulcroft RA, Jensen MP, Hops H. Observational assessment of chronic pain patient-spouse behavioral interactions. Behav Ther 1991;22:549-67.

79. Romano JM, Turner JA, Jensen MP, et al. Chronic pain patientspouse behavioral interactions predict patient disability. Pain 1995;63:353-60.

80. Derryberry D, Reed MA. Anxiety-related attentional biases and their regulation by attentional control. J Abnormal Psychol 2002;111:225-36. 


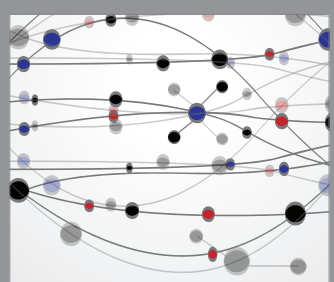

The Scientific World Journal
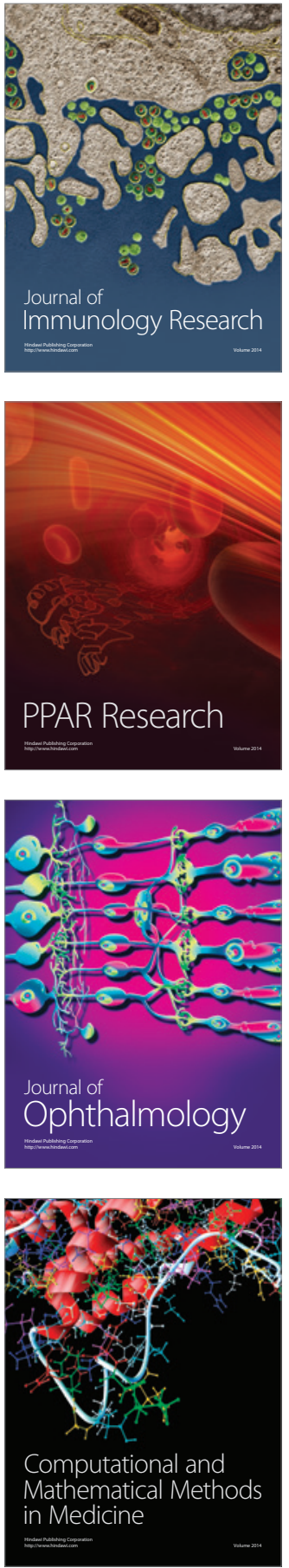

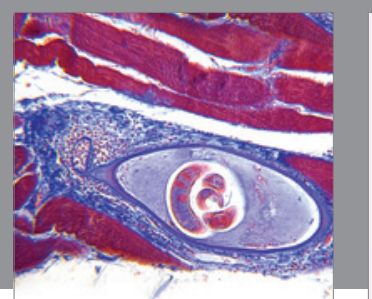

Gastroenterology Research and Practice

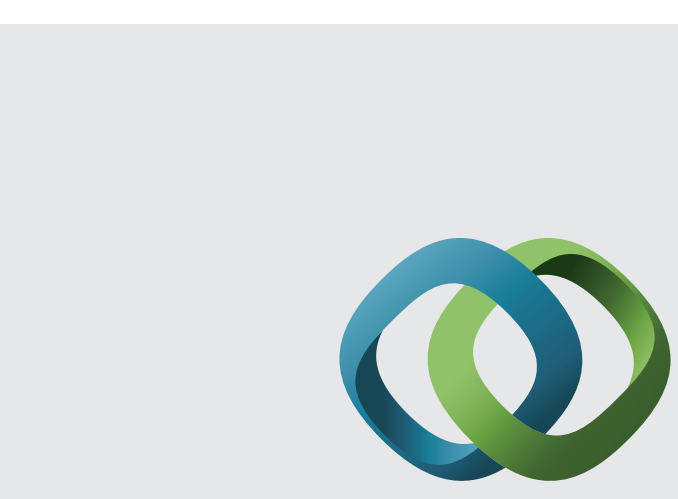

\section{Hindawi}

Submit your manuscripts at

http://www.hindawi.com
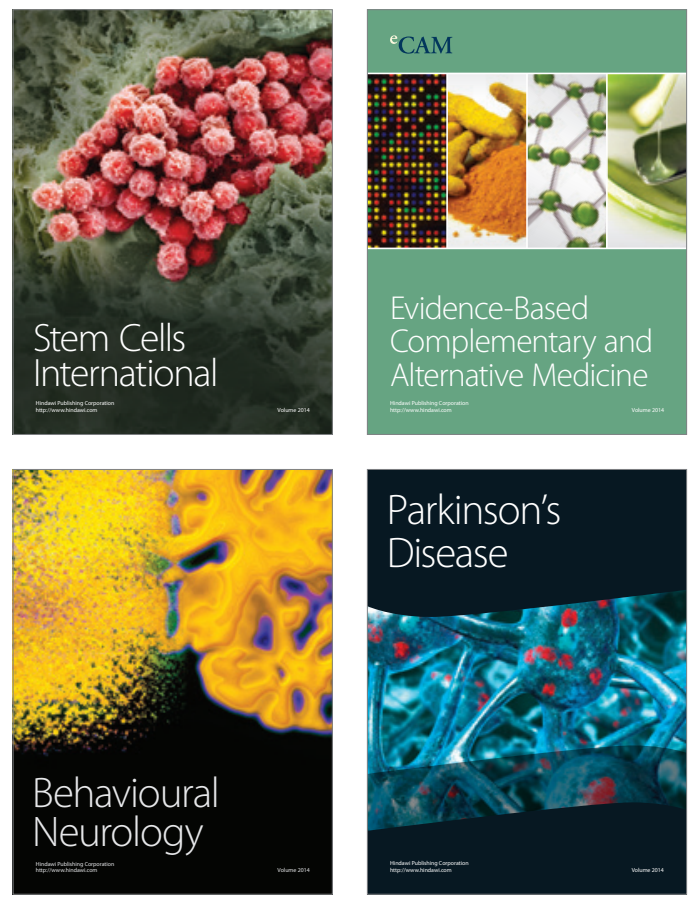
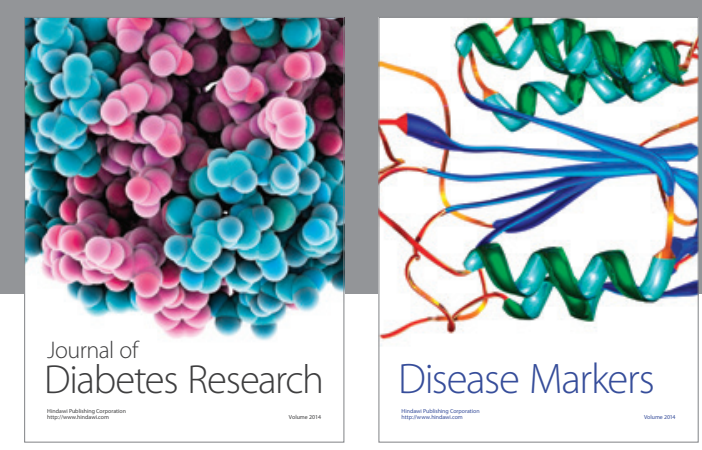

Disease Markers
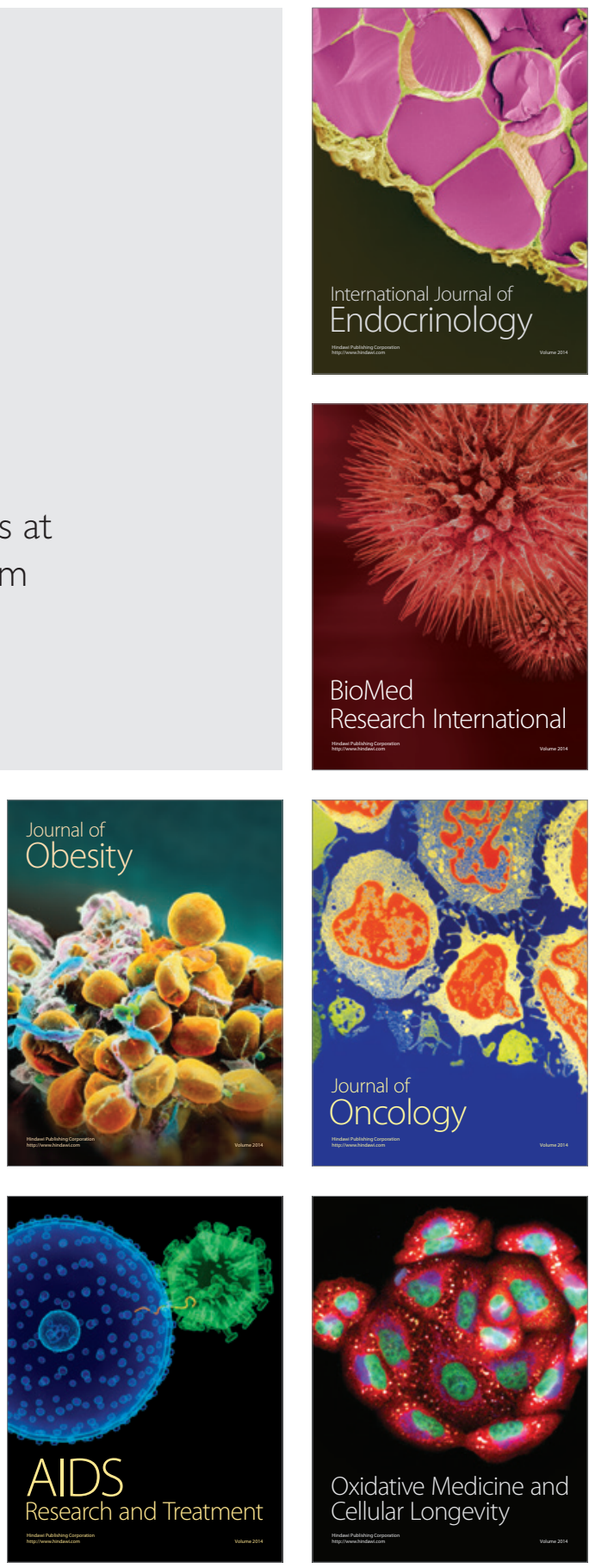